\title{
Review
}

\section{Diaphragmatic paresis: pathophysiology, clinical features, and investigation}

\section{G J GIBSON}

The function of the diaphragm has been the subject of intense study over the past 15 years. As a result its complex actions in normal subjects are now better understood and it is increasingly clear that impairment of diaphragmatic function may contribute to the pathophysiology of various conditions, not only primary neuromuscular diseases, but also skeletal abnormalities and pulmonary diseases such as asthma and chronic airways obstruction. This article is concerned with the presentation, consequences, investigation, and treatment of bilateral and unilateral diaphragmatic paralysis; it is prefaced by a brief review of current structural and functional concepts and an account of the methods available for clinical investigation of the diaphragm.

Hemidiaphragmatic paralysis is a condition familiar to chest physicians and its implications in terms of the likely underlying mediastinal lesions have been well known for many years.' The functional and symptomatic consequences have been less generally agreed, but several recent studies ${ }^{2-7}$ have helped to clarify the picture. Bilateral diaphragmatic paralysis is a much less familiar condition, which had been reported only occasionally ${ }^{189}$ until the series of Newsom Davis et al in $1976 .{ }^{10}$ With the increasing use of measurements of transdiaphragmatic pressure and diaphragmatic electromyography, bilateral diaphragmatic paralysis or severe weakness is now increasingly recognised. As an isolated abnormality, however, it remains a very rare occurrence, and recent evidence ${ }^{11}$ suggests that if the function of the other respiratory muscles is normal bilateral diaphragmatic paralysis may have less profound consequences than have formerly been described.

\section{Structure and function of the diaphragm}

Standard anatomical texts ${ }^{12}$ describe the structure of the diaphragm in terms of its central tendon and muscular domes with attachments to the lower six ribs,

Address for correspondence: Dr G J Gibson, Department of Respiratory Medicine, Freeman Hospital, Newcastle upon Tyne, NE7 7DN. to the xiphisternum and pericardium, and, via the arcuate ligaments and diaphragmatic crura, to the $\vec{\theta}$ lumbar vertebrae. Clear understanding of its action has, however, been elusive and the reasons were well $\circ$ stated by Briscoe in 1925: ${ }^{1}$

We have not to deal with a simple muscle exerting a $Z$ straightforward easily ascertained action upon fixed $\stackrel{\circ}{<}$ points, but with a double sheet of complex fibres hidden $\triangle$ deep in the body, the actions of which are far from simple and only to be recognised by effects which are not only for 으 the most part indirectly produced, but are always com- $\overrightarrow{0}$ plicated by the interfering action of other muscles.

This remains true in 1989 but understanding of the mechanisms of action of the diaphragm has been improved by a clearer perception of its topography and anatomical relations and by measurements of chest wall motion, transdiaphragmatic pressure, and $\stackrel{\mathcal{Q}}{\mathcal{O}}$ electromyography.

\section{ACTIONS OF THE DIAPHRAGM ON THE RIB CAGE} In 1973 Goldman and Mead ${ }^{13}$ pointed out that during quiet tidal breathing, particularly in the supine pos-ture, the upper surface of the diaphragm is in direct relation not to the lung but to the inner surface of the rib cage; there exists a large circumferential surface below the lungs where the two layers of parietal pleura 3 lining respectively the superior surface of the diaphragm and the inner surface of the rib cage are in $\frac{3}{3}$ intimate contact (fig 1). With a moment's thought this important point is self evident, but until then its $\triangle$ significance had not been generally appreciated, per- $\frac{\rightarrow}{2}$ haps because the clinician is used to examining chest radiographs taken after full inspiration when this $N_{\odot}$ "zone of apposition" is minimal. The functional consequence is that, particularly in the supine position, the lower rib cage behaves during tidal breathing $\omega$ as if it is driven by transabdominal rather than? transthoracic pressure. ${ }^{13}$ During inspiration the dia $\leftarrow$ O phragmatic muscle fibres shorten and the diaphragm $\mathbb{\Phi}$ as a whole moves caudally in piston like fashion; the ${ }^{?}$ dome of the diaphragm normally changes size or shape $\frac{T}{T}$ very little during tidal breathing and the changes in muscle length are accommodated mainly by increasing? and decreasing the area of apposition. As the dia- $\propto$ 


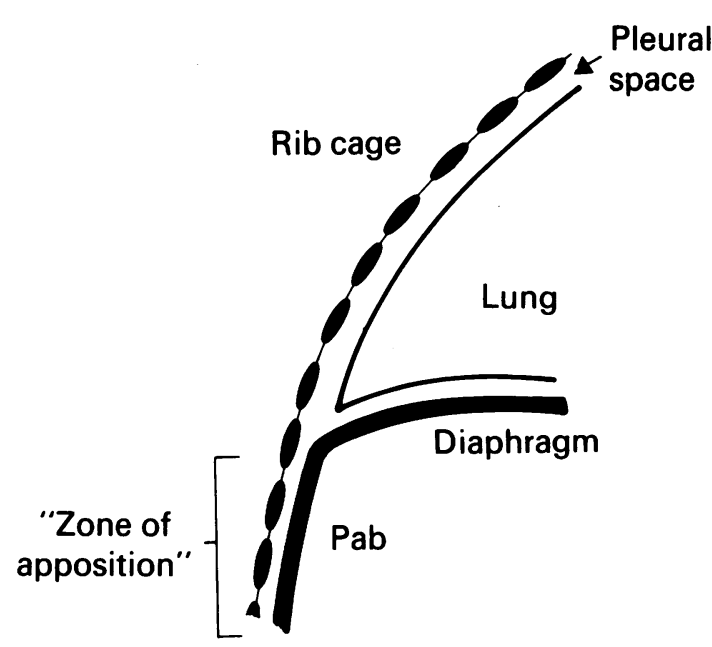

Fig 1 Diagrammatic representation of the "zone of apposition," where the lower rib cage is effectively exposed to abdominal pressure (Pab) as there is no lung intervening between the two layers of parietal pleura. These conditions apply particularly at low lung volumes and in the supine position.

phragm contracts it lowers pleural pressure and increases abdominal pressure. The reduction in pleural pressure produces an inflationary effect on the lungs but, if no other force were active, its effect on the rib cage would be deflationary. This is, however, more than countered by the accompanying effects of increasing abdominal pressure, which tends to expand the rib cage via the zone of apposition, and by the direct insertional effect of the diaphragm on the lower ribs, again tending to expand the rib cage (fig 2). In the hyperinflated chest of a patient with airways obstruction the zone of apposition is greatly diminished or absent, so that the inflationary effect of increasing abdominal pressure on the rib cage is no longer operative; in addition, the insertional effect is modified so that direct traction by the flattened diaphragm results in paradoxical inspiratory indrawing of the lower costal margin (Hoover's sign ${ }^{14}$ ).

\section{INTERACTION OF DIAPHRAGM AND OTHER RESPIRATORY MUSCLES}

Although the diaphragm is the most important inspiratory muscle, it is not the only one active during quiet breathing. The presence of phasic electrical activity in the inspiratory intercostal muscles has long been recognised and similar activity has more recently been reported in the scalene muscles, which are more appropriately regarded as primary inspiratory muscles rather than as accessory muscles of inspiration. ${ }^{15}$ During deeper or more forceful inspiratory efforts other muscles, such as the sternomastoids, are recruited. In lung disease resting ventilation is usually increased and the impedance to breathing may be abnormally high, so that coordinated contraction of both the primary and the accessory muscles of inspiration is necessary.

In bilateral diaphragmatic paralysis inspiration is achieved by the inspiratory intercostal and accessory muscles, which lower pleural pressure and expand the

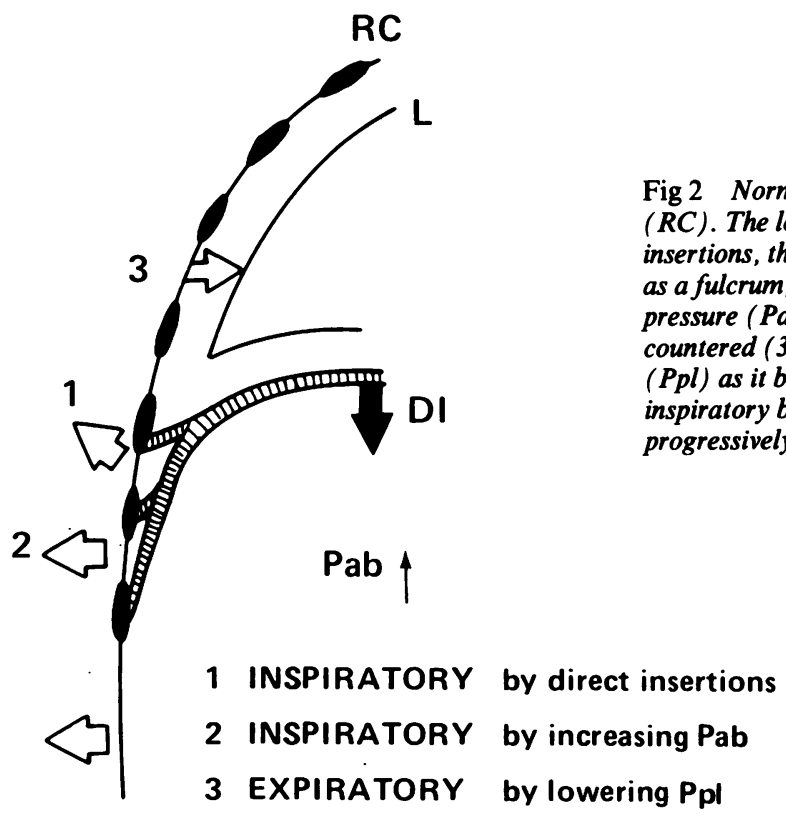

Fig 2 Normal effects of the diaphragm on the rib cage (RC). The lower rib cage is expanded (1) by direct insertions, the diaphragm (DI) using the abdominal contents as a fulcrum, and (2) by the effect of increasing abdominal pressure (Pab) via the zone of apposition; these effects are countered (3) by the deflating effect of pleural pressure (Ppl) as it becomes more negative. The net effect is inspiratory but mechanisms (1) and (2) become progressively less effective as lung volume increases. 
INSPIRATION WITH

DIAPHRAGM ALONE

Movements
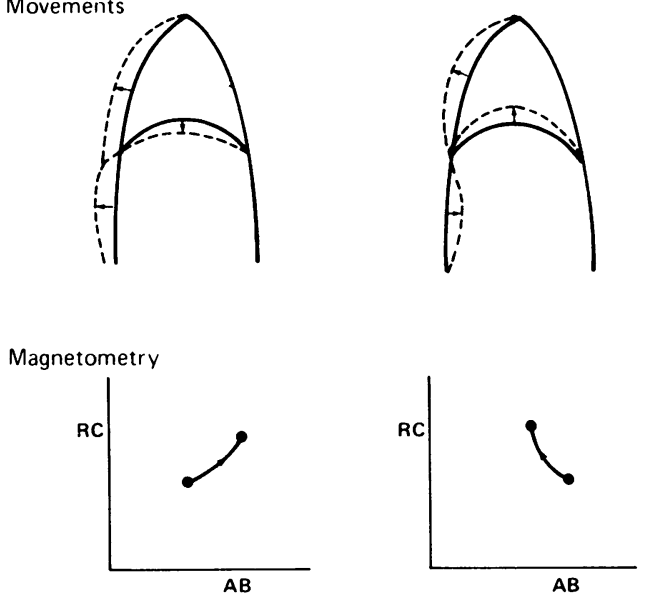

Pressures

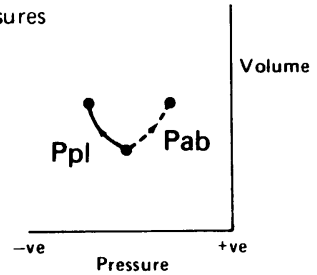

INSPIRATION WITHOUT DIAPHRAGM
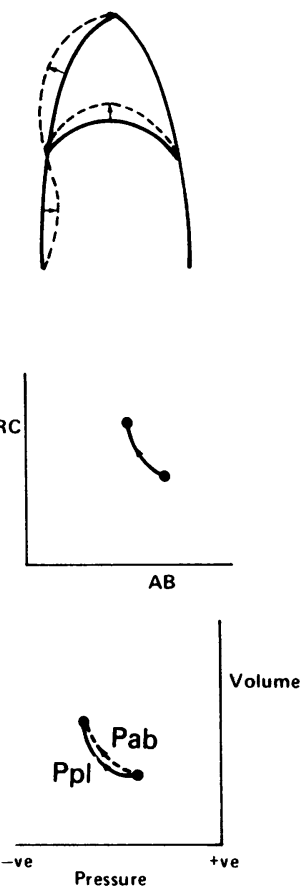

Fig 3 Comparison of chest wall motion and pleural and abdominal pressure changes when inspiration is achieved by the diaphragm (left) and by other inspiratory muscles in complete diaphragmatic paralysis (right); with diaphragmatic contraction both rib cage $(R C)$ and abdominal $(A B)$ dimensions increase and abdominal pressure (Pab) becomes more positive. With bilateral diaphragmatic paralysis the rib cage and abdomen move out of phase with each other-that is, abdominal paradox occurs and abdominal pressure passively follows pleural pressure (Ppl).

rib cage. The flaccid diaphragm moves cranially and subdiaphragmatic abdominal pressure becomes more negative, rather than more positive as occurs with normal diaphragmatic contraction (fig 3). The muscles of the abdominal wall, which are normally expiratory, may also act as accessory muscles of inspiration. Expiratory abdominal muscle contraction is common in patients with bilateral diaphragmatic weakness and it has been suggested that use of these muscles might aid inspiration by producing ascent of the paralysed diaphragm at the end of expiration, so that when abdominal contraction ceases the diaphragm descends passively at the onset of inspiration. ${ }^{1016}$ This mechanism operates effectively only in the upright position, where gravity aids passive diaphragmatic descent. Similar use of the abdominal muscles to aid inspiration has been demonstrated in normal subjects during

exercise; their activation in late expiration passively $\overrightarrow{\vec{F}}$ raises and stretches the diaphragm, in effect "priming" $\overline{0}$ it for the subsequent inspiration. ${ }^{17} \mathrm{~A}$ further example 흥 of compensatory action by a different group of $\overline{\frac{5}{3}}$ respiratory muscles in the face of diaphragmatic $\vec{\otimes}$ paralysis is glottal closure at end inspiration, which $\frac{\circ}{0}$ allows maintenance of lung volume without continu- $\infty$ ing contraction of the inspiratory muscles. ${ }^{16}$

\section{INDEPENDENCE OF RIGHT AND LEFT}

HEMIDIAPHRAGMS

As the diaphragm forms one continuous musculo- $x$ tendinous sheet between the thorax and the abdomen, $\stackrel{f}{+}$ it is at first sight surprising that each hemidiaphragm can apparently operate independently; paralysis of $\overline{0}$ one phrenic nerve might be expected to have little effect because tension in the whole diaphragm should 응 be maintained by activity in the contralateral phrenic nerve. Clearly this is not the case, however, and an $Z$ elegant computed tomography reconstruction of the human diaphragm in vivo obtained in one normal $\stackrel{\Phi}{3}$ subject by Whitelaw ${ }^{18}$ has helped understanding of how the two halves of the diaphragm can operate relatively independently when one half is paralysed. $\stackrel{\oplus}{\oplus}$ In particular, the reconstruction emphasises the pos- $\odot$ terior indentation of the central saddle shaped area of $\square$ the diaphragm by the spinal column and aorta, which together extend approximately half way across the anteroposterior diameter (fig 4). As a result, fibres project from the centre of each dome to the ipsilateral $\$$ hemithorax round more than $270^{\circ}$. The very limited $\stackrel{2}{\Rightarrow}$ projection to the contralateral hemithorax would have $\stackrel{ }{3}$ the effect that tension on one side was not well transmitted to the other, so would allow relativelyo

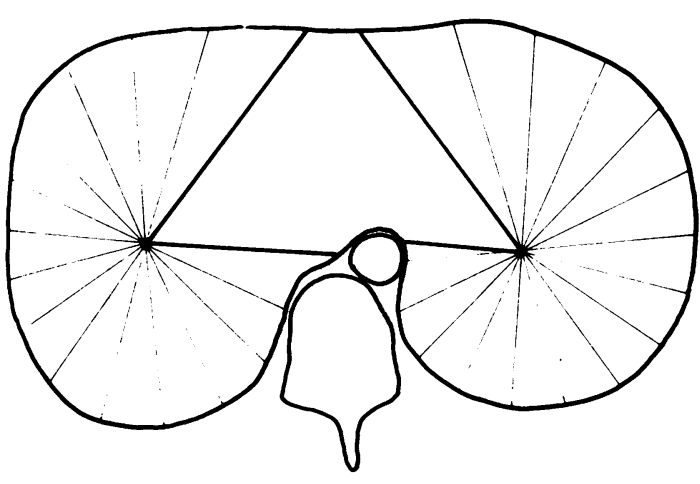

Fig 4 Direction of lines of tension from the centre of each hemidiaphragmatic dome to fixed attachments, based on the computed tomography reconstruction by Whitelaw..$^{18}$ Because lines of tension project to the opposite hemidiaphragm only via the narrow isthmus between the spine and the xiphoid process tension on one side is not well transmitted to the other. (Reproduced by courtesy of the Journal of Applied Physiology.) 
independent operation of the two halves of the diaphragm.

\section{COSTAL AND CRURAL PORTIONS: THE CONCEPT} OF "TWO DIAPHRAGMS",

A further important conclusion on structurefunction relationships of the diaphragm has come recently from studies in dogs ${ }^{19}$ showing that stimulation of the costal and crural portions individually produces very different effects: in the supine animal contraction of the costal fibres at resting lung volume increased rib cage dimensions but contraction of the crural fibres did not; at higher lung volumes, or when the abdomen was opened to the atmosphere (so that the inflating effect on the rib cage of increasing abdominal pressure could no longer operate), stimulation of the crural diaphragm led to diminution of rib cage dimensions. The concept of the diaphragm as two functionally independent muscles has an embryological counterpart as the costal diaphragm develops from the lateral body wall whereas the crural portion develops in the dorsal mesentery of the oesophagus. ${ }^{12}$ This finding has led to a more complex but more realistic model of inspiratory muscle actions ${ }^{20}$; the implications for diaphragmatic function in healthy man or in disease remain to be explored.

\section{Methods of assessment}

\section{CLINICAL METHODS}

Clinical assessment of diaphragmatic function is at best crude. The effect of the diaphragm on tidal breathing is most apparent in the supine posture, where the abdominal muscles are usually least active; the normal forward motion of the anterior abdominal wall results directly from displacement of the abdominal contents by contraction of the diaphragm. Patients with bilateral diaphragmatic paralysis complain of extreme orthopnoea and (if they can tolerate being examined supine) there is obvious inspiratory paradoxical motion of the abdominal wall, resulting from passive transmission of the negative pleural pressure generated by the other inspiratory muscles. Palpation of the abdominal wall allows this effect to be distinguished from active contraction of the abdominal muscles themselves. In unilateral paralysis asymmetry of abdominal wall motion or diminution of expansion of the ipsilateral costal margin during a deep inspiration can sometimes be detected but these signs are insensitive and unreliable. The maximum excursion of the diaphragm between full inspiration and full expiration can be assessed approximately by percussion, but this is of limited value. Reduced motion on one side is very non-specific and occurs with localised disease above or below the diaphragm; occasionally the paradoxical movement of unilateral paralysis can be detected.

\section{IMAGING TECHNIQUES}

Normal ranges have been established for the radiographic position and degree of curvature of the diaphragm, ${ }^{21}$ but use is made of these mainly in recognition and assessment of hyperinflation of the lungs associated with airways obstruction. An unusually high position of one or both hemidiaphragms is less specific. Provided that the patient has taken a full inspiration, bilateral elevation of the diaphragms implies one of the following: a reduction in pulmonary compliance, reduction in abdominal compliance, pleural adhesions, or weakness of the diaphragmatic muscle itself. Unilateral elevation is seen with local lesions above or below the diaphragm, with hemidiaphragmatic weakness or paralysis, or other abnormalities of the diaphragm such as eventration.

Fluoroscopy is the best established method of assessing diaphragmatic function and it retains its value in the recognition of hemidiaphragmatic paralysis. In a classic study Alexander ${ }^{22}$ investigated diaphragmatic movements in a large number of normal subjects and showed that over the full vital capacity range there were appreciable differences in most individuals between the excursions of the left and right hemidiaphragms, with movement of the left usually exceeding that of the right. He also established normal ranges for the "sniff" test: out of 776 normal subjects as many as 88 showed paradox of one or both halves of the diaphragm during sniffing. Lateral fluoroscopy showed that in some individuals the paradoxical motion was confined to the anterior part of the diaphragmatic dome with normal movement posteriorly. After exclusion of these subjects, and also any who showed paradoxical motion of both hemidiaphragms, there were still $6 \%$ of normal subjects in this series with paradoxical motion of one complete hemidiaphragm during the sniff test; this was seen more commonly on the right side. Results of fluoroscopy therefore have to be interpreted with some caution; paradoxical motion should be at least $2 \mathrm{~cm}$ for the confident recognition of abnormality. With bilateral paralysis fluoroscopy is less helpful, at least in the upright posture, as apparently normal inspiratory movement may be seen with passive descent after relaxation of the abdominal wall muscles, which have contracted during the previous expiration. ${ }^{23}$

Ultrasonography shows the right dome of the diaphragm well, but the left hemidiaphragm is visualised less clearly as the underlying bowel transmits ultrasound less well than does the liver. Most ultrasonic images of the diaphragm are obtained incidentally during investigation of possible ab- 
dominal or pleural abnormalities. Parasagittal images are obtained by scanning in B mode with the subject in the supine position; the transducer is placed subcostally and directed towards the head as a gentle arc is sectored. ${ }^{24}$ Normal values for the range of displacement of the right hemidiaphragm between functional residual capacity (FRC) and total lung capacity (TLC) in supine subjects have been established..$^{25}$ In many subjects three distinct echogenic lines are seen in the region of the right hemidiaphragm, particularly at high lung volumes: the inferior of these lines has been shown to represent the liver capsule and diaphragm and the middle line the lung and visceral pleura, and the superior line to be a mirror image artefact of the inferior line. ${ }^{26}$ Little use has so far been made of ultrasonography in clinical assessment of the diaphragm, but it has been used in combination with phrenic nerve stimulation as a means of following the recovery of diaphragmatic paralysis in infants. ${ }^{27}$

Computed tomography has been used to estimate the thickness of the diaphragmatic leaves and the height of the dome; both show large ranges in normal subjects. ${ }^{28}$ Conventional computed tomography images obtained in transverse section show the diaphragmatic crura well; reconstructions of images in the sagittal or coronal planes give more accurate information on the thickness and composition of the diaphragmatic dome and have been used in detailed reconstruction of diaphragmatic topography ${ }^{18}$ (see above). So far no clinical use appears to have been made of this approach, nor has the possible role of magnetic resonance imaging been evaluated.

\section{VOLUME AND PRESSURE MEASUREMENTS}

Earlier reports drew attention to the substantial change in vital capacity (VC) between erect and supine positions as an indicator of bilateral diaphragmatic paralysis. ${ }^{910}$ In such patients VC characteristically falls by half or more when the subject is lying supine. Normal subjects, however, also show a reduction of VC in the supine posture, which is reported to be as much as $20 \%$. $^{29}$ Differences of $20-50 \%$ suggest diaphragmatic weakness and indicate the need for further assessment. Measurements of the expansion of the rib cage and abdomen individually give indirect information about the contribution of the diaphragm to tidal breathing. The ratio of rib cage and abdominal displacement (measured by magnetometers or inductance plethysmography) has been used as an index of diaphragmatic function. With complete bilateral paralysis the ratio is negative as the abdomen moves completely out of phase with the rib cage (fig 3 ). Displacements of the rib cage and abdomen are not, however, specific as they are influenced also by contraction of the other groups of respiratory muscles (intercostal and accessory muscles, abdominalos muscles).

The tension developed by the diaphragm cannot beo measured directly but the pressure generated by its contraction is readily accessible. Measurements of transdiaphragmatic pressure (Pdi) were introducedo by Agostoni and Rahn. ${ }^{30}$ Pleural pressure $(\mathrm{Ppl})$ is estimated from oesophageal pressure measured in the $\vec{\circ}$ conventional way with an oesophageal balloon; sub- $\overrightarrow{-}$ diaphragmatic abdominal pressure $(\mathrm{Pab})$ is derived from gastric pressure (Pga) measured by a second balloon in the stomach. Pga is consistently more positive than Pab, partly because of the hydrostatic pressure gradient and partly because of tone in the gastric wall. Most investigators assume that Pdi ate FRC is zero-that is, $\mathrm{Ppl}=\mathrm{Pab}$; hence $\mathrm{Pab}$ during breathing is derived from Pga by subtracting thes difference between Pga and Ppl recorded with thesubject relaxed at FRC.

The value of Pdi recorded during a maximum static inspiratory effort is not necessarily the highest value a subject can attain as the pattern of performing a@ forceful inspiratory effort shows considerable variation between subjects. ${ }^{31}{ }^{32}$ Some subjects activate theog rib cage and accessory muscles to a relatively greater ${ }^{\circ}$ extent than the diaphragm so that Pab tends to become more negative during the effort and dia-s phragmatic strength may be underestimated, whereasō in other subjects Pab becomes strongly positive. Thiso variability limits the clinical usefulness of maximum $\mathbb{\perp}$ Pdi measured during such manoeuvres.

Miller et $a l^{33}$ showed in normal subjects that 3 measurement of Pdi during maximal sniffs at FRC produced consistently larger values than those recor-0. ded during sustained maximum static inspiratory efforts at residual volume and the resulting normalo range showed less variation between subjects. Even $\underset{\times}{\stackrel{0}{0}}$ during sniffs, however, the associated change in Pabo has been shown to contribute a proportion of the recorded Pdi, varying in normal subjects from $14 \%$ too $80 \% \cdot{ }^{34}$ In some subjects the greatest value of Pdi may be found during expulsive manoeuvre ${ }^{30}$ or during theo "diaphragmatic Müller manoeuvre"-that is, when $\square$ the subject performs a maximum inspiratory effort ato the same time concentrating on producing forward abdominal motion..$^{35}$ The maximum values achieved ${ }^{\circ}$ can be increased by providing visual feedback infor- $N$ mation to the subject with an oscilloscope displaying Ppl and Pab to encourage maximal effort. ${ }^{36}$ The mosto appropriate method of assessing maximal diaphrag matic activation in clinical practice is not universally agreed. The sniff technique requires least training, whereas the static feedback method ${ }^{36}$ tends to give the $\square$ greatest values of Pdi and the subject's spontaneouso inspiratory effort consistently produces the most $\vec{\otimes}$ negative pleural pressure. 
Diaphragmatic contraction during quiet tidal breathing is normally associated with an increase in $\mathrm{Pab}$ and reduction in $\mathrm{Ppl}$ so that the contribution of the diaphragm can be assessed semiquantitatively by examining the ratio $\Delta \mathrm{Pab}: \Delta \mathrm{Ppl} .{ }^{37} \mathrm{This}$ analysis is valid only if other respiratory muscles do not contribute appreciably to the pressures generated. The ratio is normally negative as $\mathrm{Ppl}$ and $\mathrm{Pab}$ move in opposite directions (fig 3, left); it becomes positive if $\mathrm{Pab}$ falls (that is, becomes more negative) during inspiration. The ratio has a maximum value of +1 when the diaphragm makes no contribution to the breath-that is, if $\Delta \mathrm{Ppl}$ and $\Delta \mathrm{Pab}$ are equal (fig 3 , right). The measurement is of particular value in patients who are unable or unwilling to perform maximal efforts. ${ }^{7}$

\section{Electrophysiological techniques}

Electromyographic activity in the diaphragm can be recorded with either oesophageal or surface electrodes. The former is less convenient but can be combined with measurements of transdiaphragmatic pressure with a single catheter system. ${ }^{38}$ Surface electrodes are more generally used. Recordings are made during spontaneous breathing or during electrical stimulation of the phrenic nerve in the neck. ${ }^{39}$ The latter is subject to the theoretical disadvantage that lack of response may represent failure to locate the phrenic nerve, but in practice this is rarely a problem with an experienced operator. ${ }^{40}$ The normal phrenic nerve conduction time in adult subjects is less than $9.5 \mathrm{~ms} .{ }^{41}$ Phrenic nerve stimulation can be combined with measurement of transdiaphragmatic pressure to assess the mechanical response to neural excitation. ${ }^{4243}$ Stimulation may be unilateral or simultaneously bilateral; it may use either a single "twitch" or a sustained tetanic discharge, but the latter is rarely used as it causes discomfort. The values of Pdi resulting from phrenic nerve stimulation are appreciably lower than those obtained by voluntary efforts; the pressure during bilateral stimulation exceeds the sum of the values recorded with sequential unilateral stimulation, and that obtained with a tetanic discharge is greater than with a twitch. This approach has a role in distinguishing diaphragmatic paresis due to upper motor and lower motor neurone lesions ${ }^{44}$; in the former a disproportionate reduction of voluntary Pdi would be expected, whereas in the latter case values obtained after stimulated and voluntary contraction should be impaired to a similar degree.

\section{Bilateral diaphragmatic paralysis}

Paralysis or severe weakness of both hemidiaphragms is seen usually in the context of severe generalised respiratory muscle weakness, but in occasional patients the diaphragm is specifically or disproportionately affected. Conditions that are particularly associated with bilateral diaphragmatic paralysis are listed in the table. Most are rare and the association with bilateral diaphragmatic paralysis is in many instances based only on isolated case reports, but a few of these conditions merit individual mention.

In motor neurone disease of the common adult type (amytrophic lateral sclerosis) the respiratory muscles are usually affected in proportion to the extent of the disease elsewhere ${ }^{48}$ but occasionally early paralysis of the diaphragm presents diagnostic difficulty. ${ }^{79}$ The phrenic nerves are probably affected quite commonly in generalised polyneuropathies but often this is not apparent unless phrenic nerve function is specifically studied, as recently with hereditary peroneal muscular atrophy (Charcot-Marie-Tooth syndrome).$^{534}$ With acute infective (Guillain-Barré) polyneuropathy recovery of phrenic nerve function is not always complete and this may become apparent as difficulty in weaning a patient from ventilatory support when neural function elsewhere appears to be recovering. The syndrome of neuralgic amyotrophy ("paralytic brachial neuritis") is one of the more common causes of isolated bilateral diaphragmatic paralysis ${ }^{11556}$; it is associated with pain, muscle wasting, and sensory loss in the shoulder or arm; again, recovery of diaphragmatic function is often incomplete. ${ }^{56}$ Phrenic nerve injury by cold (the "frostbitten phrenic") has been reported on several occasions after open heart sur-

Conditions particularly associated with bilateral diaphragmatic paresis

\begin{tabular}{|c|c|c|}
\hline $\begin{array}{l}\text { Site of } \\
\text { lesion }(s)\end{array}$ & Condition & References \\
\hline Spinal cord & $\begin{array}{l}\text { Transection above C5 } \\
\text { Multiple sclerosis }\end{array}$ & $\begin{array}{l}45 \\
46\end{array}$ \\
\hline Motor neurones & $\begin{array}{l}\text { Poliomyelitis } \\
\text { Amyotrophic lateral sclerosis } \\
\text { Spinal muscular atrophy }\end{array}$ & $\begin{array}{l}47,48 \\
16,49,50\end{array}$ \\
\hline $\begin{array}{l}\text { Cervical nerve } \\
\text { roots }\end{array}$ & Severe spondylosis & 51 \\
\hline Phrenic nerves & $\begin{array}{l}\text { Tetanus antitoxin } \\
\text { Guillain-Barré polyneuropathy } \\
\text { Charcot-Marie-Tooth polyneuropathy } \\
\text { Neuralgic amyotrophy } \\
\text { Unclassified phrenic neuropathy } \\
\text { Trauma: blunt chest injury } \\
\text { cold injury } \\
\text { Malignant invasion } \\
\text { Paraneoplastic lesion } \\
\text { Hypothyroidism }\end{array}$ & $\begin{array}{l}8 \\
41,52 \\
53,54 \\
11,55,56 \\
57,58,59 \\
60 \\
41,61,62 \\
63 \\
64 \\
65,66\end{array}$ \\
\hline $\begin{array}{l}\text { Diaphragmatic } \\
\text { muscle }\end{array}$ & $\begin{array}{l}\text { Limb girdle dystrophy } \\
\text { Acid maltase deficiency } \\
\text { Systemic lupus erythematosus } \\
\text { Mixed connective tissue disease } \\
\text { Dermatomyositis } \\
\text { Systemic sclerosis } \\
\text { Amyloid infiltration }\end{array}$ & $\begin{array}{l}10,67 \\
68,69 \\
70-74 \\
75 \\
76 \\
77 \\
78\end{array}$ \\
\hline
\end{tabular}


gery ${ }^{6162}$; it results from ice used in the pericardium to produce topical cardiac cooling. The condition comes to light with postoperative difficulty in weaning from ventilatory support; recovery is usual but may take several months. ${ }^{62}$

The diaphragm is likely to be affected in virtually any generalised disease of skeletal muscle: conditions with a propensity to cause disproportionate diaphragmatic weakness are the late onset form of muscular dystrophy (limb girdle dystrophy) ${ }^{1067}$ and acid maltase deficiency. ${ }^{689}$ In the more common juvenile form of muscular dystrophy, Duchenne muscular dystrophy, diaphragmatic paralysis tends to be a late feature. Respiratory muscle function is affected in many systemic conditions, particularly the collagen diseases and thyroid disease. Occasional patients with systemic lupus erythematosus develop the interesting "shrinking lung" syndrome, characterised by dyspnoea, orthopnoea, and radiographic elevation of the hemidiaphragms, which on screening are said to move "sluggishly." Several studies ${ }^{70-74}$ have suggested that this syndrome results most commonly from severe diaphragmatic weakness; extensive fibrosis and atrophy of the diaphragm was found at necropsy in one case. ${ }^{72}$ The condition deteriorates when the disease is active generally but may stabilise during prolonged periods of chronic disability.

Patients with bilateral diaphragmatic paralysis usually complain of breathlessness but in the presence of severe generalised muscle weakness the capacity to perform exercise may be so limited that this is not a major feature. Orthopnoea is a more specific symptom and is sometimes so severe that the patient is unable to lie completely supine. There is associated tachypnoea, respiratory distress, and abdominal wall paradox in the supine position. The chest radiograph typically shows elevation of both hemidiaphragms, though this is not always present; atelectasis may be evident at the lung bases. Fluoroscopy may show apparently diminished movement but is generally unhelpful, at least in the upright posture ${ }^{23}$; if it is performed with the subject supine diaphragmatic paradox is more readily detected.

Newsom Davies et $a l^{10}$ drew attention to the elevation of arterial carbon dioxide tension in their patients, particularly in the supine position, and the arterial blood gases showed striking deterioration when the subjects were asleep. Similar findings were reported by Skatrud et $a l^{67}$ in one patient with limb girdle dystrophy studied in detail during sleep, when there was considerable hypoventilation during rapid eye movement (REM) sleep. As in normal subjects ventilation during REM sleep is dependent on activity of the diaphragm, because the intercostal and accessory muscles are then inactive ${ }^{80}$ it was suggested that patients with diaphragmatic paralysis would be unusually vulnerable to hypoventilation or apnoea, $\stackrel{\overrightarrow{5}}{\stackrel{\vec{S}}{+}}$ particularly during REM sleep. Recently, however, Laroche et al, " studying six carefully chosen patients in a stable state with severe and apparently isolated bilateral diaphragmatic weakness, found neither chronic hypercapnia nor abnormal nocturnal hypoventilation. They therefore argued that the nocturnal hypoventilation reported in other studies was dependent on the presence of generalised respiratory muscle weakness and that bilateral diaphragmatic paralysis alone does not lead to important nocturnal hypoventilation or chronic respiratory failure. This controversy is not completely resolved as there are other well documented cases with apparently isolated bilateral diaphragmatic paralysis where hypercapnia was present. ${ }^{6063}$

Because in most patients bilateral diaphragmatic paralysis occurs in the context of global respiratory muscle weakness, many patients are adequately assessed by simple measurements of maximum static respiratory pressures at the mouth. In the occasional patient in whom specific or disproportionate weakness of the diaphragm is suspected measurements of Pdi are indicated. When the diaphragms are completely paralysed the exact manoeuvres used to detect Pdi are not critical; with weakness, however, measurements of Pdi, especially during forceful efforts, may need to be interpreted cautiously. Mier et $a l^{81}$ investigated the interrelations of various indices of diaphragmatic function in 30 patients with varying degrees of diaphragmatic weakness; they showed general correlations between maximum inspiratory pressure (PImax) measured at the mouth (an index of global inspiratory muscle function) and Pdi during forceful sniffing. Reduction of the latter was also related to the presence of abdominal paradox and to $\triangle \mathrm{VC}$ in the supine posture. When sniff Pdi was less than $30 \mathrm{~cm} \mathrm{H}_{2} \mathrm{O}$ orthopnoea and abdominal paradox were always present. Although these clinical features are, of course, not specific, the presence of severe bilateral diaphragmatic weakness is likely to be detected by a combination of clinical examination and measurements of $\triangle \mathrm{VC}$ and PImax; measurement of Pdi is available for confirmation if necessary. If the cause of the paralysis is uncertain phrenic nerve stimulation with measurement of the electromyographic or pressure (Pdi) response and phrenic nerve conduction time may be helpful in locating the site and nature of the lesion or lesions.

The management of patients with bilateral diaphragmatic paralysis is determined by the nature of the underlying condition. Occasionally, as in the case of infective polyneuropathy, the paresis is reversible; but more often recovery cannot be expected. In occasional patients, where the cause is situated proximally in the upper cervical cord or brainstem, pacing 
of the distal phrenic nerves may be appropriate. ${ }^{82}$ In the context of generalised muscle disease ventilatory assistance may be indicated particularly during sleep, and this may lead to an improvement in daytime respiratory function. Traditionally this has been achieved by negative pressure ventilation using a cuirass, ${ }^{83}$ but more recently the technique of intermittent positive pressure ventilation via a nasal mask has proved successful in many patients and seems likely to become the treatment of choice. ${ }^{8485}$

\section{Unilateral diaphragmatic paralysis}

Hemidiaphragmatic paralysis is much more familiar to the chest physician than is bilateral paralysis. In many cases the cause is immediately evident from the history or chest radiograph. Formerly therapeutic phrenicotomy was a common cause and the effects of this procedure are still seen in a few patients who were treated for tuberculosis in the preantibiotic era. The commonest single identifiable cause nowadays is malignant infiltration due to a bronchial carcinoma. This was the diagnosis in one third of 105 patients with paralysis of identifiable cause reported by Piehler $e t$ $a l^{3}$ A further third of these patients had a history of thoracic or neck operations resulting in intentional or accidental phrenic nerve injury, and the remaining third had diaphragmatic paralysis related to trauma, infection, or neurological disease. Most of the causes of bilateral paralysis listed in the table may present as apparent unilateral paralysis: cases have been reported, for instance, with spinal cord injury, ${ }^{86}$ cervical spondylosis, ${ }^{87}$ poliomyelitis ${ }^{88}$ neuralgic amyotrophy ${ }^{55}$ and late onset muscular dystrophy. ${ }^{89}$ Other specific causes of unilateral paralysis include pneumonia, ${ }^{88}$ trauma resulting from cannulation of the subclavian vein, ${ }^{90}$ and herpes zoster affecting the cervical nerve roots and associated with a characteristic vesicular rash over the appropriate dermatomes. ${ }^{9192}$

Whether hemidiaphragmatic paralysis in itself is a sufficient explanation for breathlessness during exertion has been a matter of some dispute, but in a series of 142 such patients with no identifiable cause $24 \%$ complained of shortness of breath and in most this was persistent. ${ }^{3}$ If there is concomitant obesity or lung disease, such as airflow obstruction, the symptomatic impact is greater. Orthopnoea is also a frequent complaint, ${ }^{2}$ but it is less dramatic than in patients with bilateral paralysis. The physical signs are usually nonspecific; occasionally paradoxical motion of the paralysed diaphragm may be suspected by percussion and there is a reduction in breath sounds at the affected lung base. Asymmetrical motion of the abdominal wall in the supine posture is occasionally detectable. $^{15}$

The functional effects of hemidiaphragmatic paralysis are in general similar to, but less striking than, those of bilateral paralysis. There are reductions in ventilation and perfusion of the lower lobe on the affected side, ${ }^{49394}$ leading to some mismatching and widening of the alveolar-arterial oxygen difference and mild hypoxaemia. ${ }^{4}$

Indices of diaphragmatic function give values intermediate between those of bilateral paralysis and normality. Some reduction in vital capacity in the sitting position is the rule but this is rarely severe, with mean values reported of $74 \%{ }^{5}$ and $81 \%^{2}$ predicted. The fall in vital capacity when the supine position is assumed is greater than normal but less than is seen in bilateral paralysis. In one subject studied in detail before and after crushing of the right phrenic nerve because of intractible hiccups Easton et $^{4} \mathrm{l}^{4}$ showed an increase in $\triangle \mathrm{VC}$ from 0.47 to $1.0 \mathrm{l}$. Clague and $\mathrm{Hall}^{2}$ in four patients with right hemidiaphragmatic paralysis showed a mean $\triangle \mathrm{VC}$ of $19 \%$, compared with $10 \%$ in four subjects with left sided paralysis; the greater fall in the individuals with right sided lesions was attributed to the weight of the liver. Pimax is reduced; Laroche et $a l^{6}$ found a mean value of $62 \%$ predicted. Maximum Pdi is also reduced, by about half both during static efforts ${ }^{5}$ and during sniffing. ${ }^{6}$ The wide normal range of Pdi during maximum static efforts, however, reduces its discriminatory value and measurements in half the patients studied by Lisboa $e t a^{6}$ were in the low normal range. During tidal breathing the changes in gastric pressure show a reduced amplitude, the pressure sometimes becoming more negative during inspiration. The latter is particularly evident with left hemidiaphragmatic paralysis, as might be expected from the normal position of the gastric air bubble under the left hemidiaphragm. ${ }^{6}$ As a result, $\Delta \mathrm{Pab} / \Delta \mathrm{Ppl}$ during tidal breathing is more positive than normal. ${ }^{67}$ The relation between $\Delta \mathrm{Pab} / \Delta \mathrm{Ppl}$ and maximum $\mathrm{Pdi}$ is similar in patients with unilateral and bilateral paralysis.? $^{\text {? }}$

The common clinical concern is whether there is an underlying serious condition in a patient who presents with hemidiaphragmatic paralysis with no cause immediately evident on the chest radiograph. The published evidence on this point is generally reassuring: in the study of Piehler et $a^{3}$ bronchoscopy was performed in 53 such cases with negative results. Nor is it likely that a cause will become evident on follow up $^{88}$; Piehler et al $^{3}$ followed 142 such patients for a mean of 8.7 years and a specific cause became apparent in only six. It was, however, noteworthy that two of these patients presented with paralysis of both the left hemidiaphragm and the left vocal cord, and in each case a carcinoma in the left lung with spread to the mediastinal nodes was subsequently diagnosed.

In patients with persisting symptoms attributable to hemidiaphragmatic palsy diaphragmatic plication is 
sometimes performed and considerable improvement in shortness of breath, together with an increase in VC and reduction in $\triangle \mathrm{VC}$, has been reported. ${ }^{95}$ Shortening and stiffening of the diaphragm restores a more normal position and reduces paradoxical motion ${ }^{95 \%}$; ventilation of the adjacent lower lobe is presumably improved and this leads to an increase in $\mathrm{PaO}_{2} \cdot{ }^{95}$ Data on diaphragmatic function are sparse, but one patient studied before and after plication showed an increase in Pdimax from 33 to $53 \mathrm{~cm} \mathrm{H}_{2} \mathrm{O}$ and more negative $\Delta \mathrm{Pab} / \Delta \mathrm{Ppl}$, falling from -0.83 to $-1 \cdot 33$. $^{7}$

The term diaphragmatic eventration is sometimes used interchangeably with diaphragmatic paralysis but is more appropriately reserved for a congenital failure of muscular development of part or all of the hemidiaphragm. It is usually left sided and presents most characteristically in infancy, when there may be associated respiratory distress requiring surgical treatment. Occasionally it is found incidentally in adult life, when it is usually asymptomatic. The distinction is readily evident at surgery, where the reduction in muscle fibres and membranous nature of the diaphragmatic partition are apparent. ${ }^{9597}$

\section{Conclusions}

Bilateral diaphragmatic paresis has been recognised for more than 60 years but only in recent years has it been generally acknowledged as an important, albeit rare, cause of respiratory disability. Its presence should be suspected by the combination of extreme orthopnoea, inspiratory abdominal paradox in the supine position, and a substantial postural fall in VC. In most cases it is seen in the context of a generalised neuromuscular disease and adequate assessment is obtained by measurements of maximum inspiratory pressure at the mouth. In a few patients measurement of Pdi or phrenic nerve conduction (or both) is justified, especially when diaphragmatic paralysis appears to be disproportionate or isolated.

Unilateral diaphragmatic paralysis is relatively common; the long established fluoroscopic sniff test remains the investigation of choice, but valid interpretation of the results requires an experienced observer and the application of certain minimum criteria for paradoxical ascent of the affected hemidiaphragm. If the likely cause is not evident from the history or chest radiograph at presentation it is unlikely to become apparent later. Many patients with hemidiaphragmatic paralysis are breathless and this can be improved by diaphragmatic plication.

\section{References}

1 Briscoe C. Diagnosis of unilateral phrenic nerve paralysis: important point in mediastinal localization. Lancet $1925 ; \mathrm{i}: 376-81$.
2 Clague HW, Hall DR. Effect of posture on lung volume: airway closure and gas exchange in hemidiaphragmatic paralysis. Thorax 1979;34:523-6.

3 Piehler JM, Pairolero PC, Gracey DR, Bernatz PE. Unexplained diaphragmatic paralysis: a harbinger of malignant disease? J Thorac Cardiovasc Surg 1982; 84:861-4.

4 Easton PA, Fleetham JA, De La Rocha A, Anthonisen NR. Respiratory function after paralysis of right hemidiaphragm. Am Rev Respir Dis 1983;127:125-8.

5 Lisboa C, Pare PD, Pertuze J, et al. Inspiratory muscle function in unilateral diaphragmatic paralysis. $\mathrm{Am} \mathrm{Rev}$ Respir Dis 1986;134:488-92.

6 Laroche C, Mier AK, Moxham J, Green M. Diaphragm strength in patients with recent hemidiaphragm paralysis. Thorax 1988;43:170-4.

7 Hillman DR, Finucane KE. Respiratory pressure partitioning during quiet inspiration in unilateral and bilateral diaphragmatic weakness. Am Rev Respir Dis 1988;137:1401-5.

8 Comroe JH, Wood FC, Kay CP, et al. Motor neuritis after tetanus anti-toxin with involvement of the muscles of respiration. Am J Med 1951;10:786-9.

9 McCredie M, Lovejoy FW, Kaltreider NL. Pulmonary function in diaphragmatic paralysis. Thorax 1962;17: 213-7.

10 Newsom Davis J, Goldman M, Loh L, Casson $M$. Diaphragm function and alveolar hypoventilation. $Q J$ Med 1976;45:87-100.

11 Laroche CM, Carroll N, Moxham J, Green M. Clinical significance of severe isolated diaphragm weakness. Am Rev Respir Dis 1988;138:862-6.

12 Williams PL, Warwick R, eds. Gray's Anatomy. 36th ed. London: Churchill Livingstone, 1980.

13 Goldman MD, Mead J. Mechanical interaction between the diaphragm and rib cage. J Appl Physiol 1973; 35:197-204.

14 Hoover CF. Diagnostic significance of inspiratory movements of costal margins. Am J Med Sci 1920;159: 633-46.

15 De Troyer A, Estenne M. Coordination between rib cage muscles and diaphragm during quiet breathing in humans. J Appl Physiol 1984;57:899-906.

16 Grinman S, Whitelaw WA. Pattern of breathing in a case of generalized respiratory muscle weakness. Chest 1983;84:770-2.

17 Grimby G, Goldman M, Mead J. Respiratory muscle action inferred from rib cage and abdominal V-P partitioning. J Appl Physiol 1976;41:739-51.

18 Whitelaw WA. Shape and size of the human diaphragm in-vivo. J Appl Physiol 1987;62:180-6.

19 De Troyer A, Sampson M, Sigrist S, Macklem PT. Action of costal and crural parts of the diaphragm on the rib cage in dog. $J$ Appl Physiol 1982;53:30-9.

20 Macklem PT, Macklem DM, de Troyer A. A model of inspiratory muscle mechanics. J Appl Physiol 1983; 55:547-57.

21 Lennon EA, Simon G. The height of the diaphragm in the chest radiograph of normal adults. $B r J$ Radiol 1965; 38:937-43.

22 Alexander C. Diaphragm movements and the diagnosis of diaphragm paralysis. Clin Radiol 1966;17:79-83. 
23 Loh L, Goldman MD, Newsom Davis J. The assessment of diaphragm function. Medicine (Baltimore) 1977;56: 165-9.

24 Haber K, Asher WM, Freimanis AK. Echographic evaluation of diaphragmatic motion in intra abdominal diseases. Radiology 1975;114:141-4.

25 Harris RS, Giovannetti M, Kim BK. Normal ventilatory movement of the right hemidiaphragm studied by ultrasonography and pneumotachography. Radiology 1983;146:141-4.

26 Lewandowski BJ, Winsberg F. Echographic appearance of the right hemidiaphragm. J Ultrasound Med 1983; 2:243-9.

27 McCauley RG. Diaphragmatic paralysis evaluated by phrenic nerve stimulation during fluoroscopy or realtime ultrasound. Radiology 1984;153:33-6.

28 Patterson NW, Teates CD. CT measurements of the anterior portions of the diaphragm with illustrative abnormal cases. Comput Radiol 1985;9:61-5.

29 Allen SM, Hunt B, Green M. Fall in vital capacity with posture. Br J Dis Chest 1985;79:267-71.

30 Agostoni E, Rahn H. Abdominal and thoracic pressures at different lung volumes. J Appl Physiol 1960;15: 1087-92.

31 Gibson GJ, Clark E, Pride NB. Static transdiaphragmatic pressures in normal subjects and in patients with chronic hyperinflation. Am Rev Respir Dis 1981; 124:685-9.

32 De Troyer A, Estenne M. Limitations of measurement of transdiaphragmatic pressure in detecting diaphragmatic weakness. Thorax 1981;36:169-74.

33 Miller JM, Moxham J, Green M. The maximal sniff in the assessment of diaphragm function in man. Clin Sci 1985;69:91-6.

34 Esau SA, Bye PTB, Pardy RL. Changes in rate of relaxation of sniffs with diaphragmatic fatigue in humans. J Appl Physiol 1983;55:731-5.

35 Roussos CS, Macklem PT. Diaphragmatic fatigue in man. J Appl Physiol 1977;43:189-97.

36 Laporta D, Grassino A. Assessment of transdiaphragmatic pressure in humans. J Appl Physiol 1985;58: 1469-76.

37 Macklem PT, Gross D, Grassino A, Roussos C. Partitioning of inspiratory pressure swings between diaphragm and intercostal/accessory muscles. $J \mathrm{Appl}$ Physiol 1978;44:200-8.

38 Onal E, Lopata M, Ginzburg AS, O'Connor TD. Diaphragmatic EMG and transdiaphragmatic pressure measurement with a single catheter. Am Rev Respir Dis 1981;124:563-5.

39 Newsom Davis $J$. Phrenic nerve conduction in man. $J$ Neurol Neurosurg Psychiatry 1967;30:420-6.

40 Mier A, Brophy C, Moxham J, Green M. Phrenic nerve stimulation in normal subjects and in patients with diaphragmatic weakness. Thorax 1987;42:885-8.

41 Markland DN, Kincaid JC, Pourmand RA, et al. Electrophysiologic evaluation of diaphragm by transcutaneous phrenic nerve stimulation. Neurology 1984;34:604-14.

42 Bellemare F, Bigland-Ritchie B. Assessment of human diaphragm strength and activation using phrenic nerve stimulation. Respir Physiol 1984;58:263-7.
43 Aubier M, Murciano D, Lecocguic Y, Viires N, Pariente R. Bilateral phrenic stimulation: a simple technique to assess diaphragmatic fatigue in humans. J Appl Physiol 1985;58:58-64.

44 Mier-Jedrzejowicz A, Green M. Respiratory muscle weakness associated with cerebellar atrophy. Am Rev Respir Dis 1988;137:673-7.

45 Ledsome JR, Sharp JM. Pulmonary function in acute cervical cord injury. Am Rev Respir Dis 1981;124:41-4.

46 Cooper CB, Trend PstJ, Wiles CM. Severe diaphragm weakness in multiple sclerosis. Thorax 1985;40:633-4.

47 Parhad IM, Clark AW, Barron KD, Staunton SB. Diaphragmatic paralysis in motor neurone disease. Neurology 1978;28:18-22.

48 Serisier DE, Mastaglia FL, Gibson GJ. Respiratory muscle function and ventilatory control. I. In patients with motor neurone disease. II. In patients with myotonic dystrophy. $Q J$ Med 1982;51:205-26.

49 Haas H, Johnson LR, Gill TH, Armentrout TS Diaphragm paralysis and ventilatory failure in chronic proximal spinal muscular atrophy. Am Rev Respir Dis 1981;123:465-76.

50 McWilliam RC, Gardner-Medwin D, Doyle D, Stephenson JBP. Diaphragmatic paralysis due to spinal muscular atrophy. An unrecognized cause of respiratory failure in infancy? Arch Dis Child 1985; 60:145-9.

51 Spiteri MA, Mier AK, Brophy CJ, Pantin CFA, Green M. Bilateral diaphragm weakness. Thorax 1985;40: 631-2.

52 Gracey DR, McMichan JC, Divertie MB, et al. Respiratory failure in Guillain-Barré syndrome. Mayo Clin Proc 1982;57:742-6.

53 Chan CK, Mohensin V, Loke J, Virgulto J, Sipski L, Ferranti R. Diaphragmatic dysfunction in siblings with hereditary motor and sensory neuropathy (CharcotMarie-Tooth disease). Chest 1987;91:567-70.

54 Laroche CM, Carroll N, Moxham J, Stanley NN, Courtenay Evans RJ, Green M. Diaphragm weakness in Charcot-Marie-Tooth disease. Thorax 1988;43: 478-9.

55 Cape CA, Fincham RW. Paralytic brachial neuritis with diaphragmatic paralysis. Neurology 1965;15:191-3.

56 Graham AN, Martin PD, Haas LF. Neuralgic amyotrophy with bilateral diaphragmatic palsy. Thorax 1985;40:635-6.

57 Spitzer SA, Korczyn AD, Kalaci J. Transient bilateral diaphragmatic paralysis. Chest 1973;64:355-7.

58 Blythe JA, Griffin JP, Gonyea EF. Bilateral diaphragmatic paralysis in association with neurogenic disease. Arch Intern Med 1977;137:1455-7.

59 Camfferman F, Bogaard JM, van der Meché FGA, Hilvering C. Idiopathic bilateral diaphragmatic paralysis. Eur J Respir Dis 1985;67:65-71.

60 Sandham JD, Shaw DT, Guenter CA. Acute supine respiratory failure due to bilateral diaphragmatic paralysis. Chest 1977;72:96-8.

61 Chandler KW. Bilateral diaphragmatic paralysis complicating local cardiac hypothermia during open heart surgery. Am J Med 1984;77:243-9.

62 Kohorst RW, Schonfeld SA, Altman M. Bilateral diaphragmatic paralysis following topical cardiac hypo- 
thermia. Chest 1984;85:65-8.

63 Kreitzer SM, Feldman NT, Saunders NA, Ingram RH. Bilateral diaphragmatic paralysis with hypercapnic respiratory failure. Am J Med 1978;65:89-95.

64 Thomas NE, Passamonte PM, Sunderrajan EV, Andelin JB, Ansbacher LE. Bilateral diaphragmatic paralysis as a possible paraneoplastic syndrome from renal cell carcinoma. Am Rev Respir Dis 1984;129:507-9.

65 Hamly FH, Timins RN, Minh VD, Moser KM. Bilateral phrenic paralysis in myxedema. Am Rev Respir Dis 1975;111:911-2.

66 Laroche CM, Cairns T, Moxham J, Green M. Hypothyroidism presenting with respiratory muscle weakness. Am Rev Respir Dis 1988;138:472-4.

67 Skatrud J, Iber C, McHugh W, Rasmussen H, Nicholas D. Determination of hypoventilation during wakefulness and sleep during diaphragmatic paralysis. Am Rev Respir Dis 1980;121:587-93.

68 Sivak ED, Salanga VD, Wilbourn AJ, Mitsumoto H, Golish J. Adult-onset acid maltase deficiency presenting as diaphragmatic paralysis. Ann Neurol 1981;9: 613-5.

69 Trend PstJ, Wiles CM, Spencer GT, Morgan-Hughes JA, Lake BD, Patrick AD. Acid maltase deficiency in adults. Brain 1985;108:845-60.

70 Gibson GJ, Edmunds JP, Hughes GRV. Diaphragm function and lung involvement in systemic lupus erythematosus. Am J Med 1977;63:926-32.

71 Martens J, Demedts M, Vanmeenen MT, Dequeker J. Respiratory muscle dysfunction in systemic lupus erythematosus. Chest 1983;84:170-5.

72 Rubin LA, Urowitz MB. Shrinking lung syndrome in SLE: a clinical pathological study. $J$ Rheumatol 1983;10:973-6.

73 Jacobelli S, Moreno R, Massardo L, Rivero S, Lisboa C. Inspiratory muscle dysfunction and unexplained dyspnoea in systemic lupus erythematosus. Arth Rheum 1985;28:781-8.

74 Wilcox PG, Stein HB, Clarke SD, Paré PD, Pardy RC. Phrenic nerve function in patients with diaphragmatic weakness and systemic lupus erythematosus. Chest 1988;93:352-8.

75 Martens J, Demedts M. Diaphragm dysfunction in mixed connective tissue disease. Scand J Rheumatol 1982; 11:165-7.

76 Schiavi EA, Roncoroni AJ, Puy RJM. Isolated bilateral diaphragmatic paresis with interstitial lung disease. An unusual presentation of dermatomyositis. Am Rev Respir Dis 1984;129:337-9.

77 Illiffe GD, Pettigrew NM. Hypoventilatory respiratory failure in generalized scleroderma. $\mathrm{Br} \mathrm{Med} J \mathrm{~J}$ 1983; 286:337-8.

78 Streeten EA, de la Monte SM, Kennedy TM. Amyloid infiltration of the diaphragm as a cause of respiratory failure. Chest 1986;89:760-2.
79 Nightingale S, Bates D, Bateman DE, Hudgson P, Ellis DA, Gibson GJ. Enigmatic dyspnoea: an unusual presentation of motor neurone disease. Lancet 1982; i:933-5.

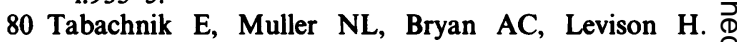
Changes in ventilation and chest wall mechanics during sleep in normal adolescents. J Appl Physiol 1981;51: क 557-64.

81 Mier-Jedrzejowicz A, Brophy C, Moxham J, Green M. Assessment of diaphragm weakness. Am Rev Respir $\vec{\omega}$ Dis 1988;137:877-83.

82 Moxham J, Potter D. Diaphragmatic pacing. Thorax 1988;43:161-2.

83 Sawicka EH, Loh L, Branthwaite MA. Domiciliary ventilatory support: an analysis of outcome. Thorax 1988;43:31-5.

84 Kerby GR, Mayer LS, Pingleton SK. Nocturnal positive pressure ventilation via nasal mask. Am Rev Respir Dis 윽 1987;135:738-40.

85 Carroll N, Branthwaite MA. Control of nocturnal hypoventilation by nasal intermittent positive pressure ventilation. Thorax 1988;43:349-53.

86 Carter RE. Unilateral diaphragmatic paralysis in spinal cord injury patients. Paraplegia 1980;18:267-74.

87 Buszek MC. Hemidiaphragmatic paralysis: an unusual complication of cervical spondylosis. Arch Phys Med Rehabil 1983;64:601-3.

88 Riley EA. Idiopathic diaphragmatic paralysis: a report of eight cases. Am J Med 1962;32:404-16.

89 Wolf E, Shochina M, Ferber I, Gonen B. Phrenic nerve and diaphragmatic involvement in progressive muscular dystrophy. Electromyogr Clin Neurophysiol 응 1981;21:35-53.

90 Obel IWP. Transient phrenic nerve paralysis following $\overrightarrow{\bar{\rho}}$ subclavian venipuncture. Anesthesiology 1970;33: 369-70.

91 Anderson JP, Keal EE. Cervical herpes zoster and diaphragmatic paralysis. Br J Dis Chest 1969;63:222-6.

93 Derveaux L, Lacquet LM. Hemidiaphragmatic paresis after cervical herpes zoster. Thorax 1982;37:870-1.

93 Arborelius M, Lilja B, Senyk J. Regional and total lung function in patients with hemidiaphragmatic paralysis. Respiration 1975;32:253-64.

94 Ridyard JA, Stewart RM. Regional lung function in unilateral diaphragmatic paralysis. Thorax 1976;31: 438-42.

95 Wright CD, Williams JG, Ogilvie CM, Donnelly RJ. Results of diaphragmatic plication for unilateral diaphragmatic paralysis. J Thorac Cardiovasc Surg 1985; 90:195-8.

96 Marcos JJ, Grover FL. Trinkle JK. Paralyzed diaphragm: effect of plication on respiratory mechanics. $J$ Surg Res 1974;16:523-6.

97 Thomas TV. Congenital eventration of the diaphragm. Ann Thorac Surg 1970;10:180-92. 